
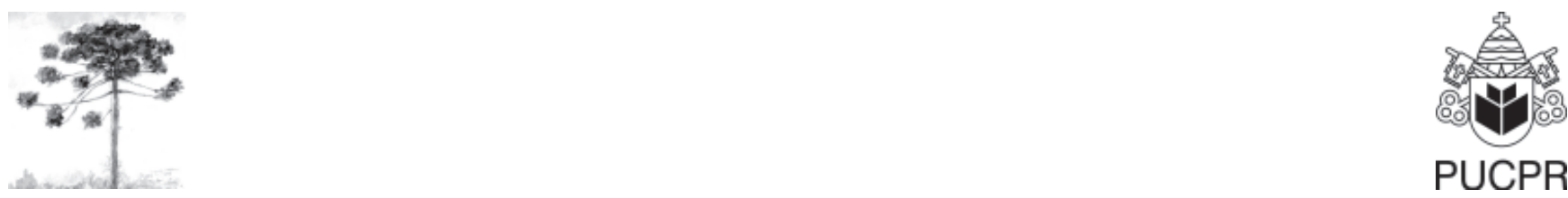

\title{
BIOLOGIA FLORAL DE Calliandra tweediei BENTH. (FABACEAE BENTH.)
}

\author{
Floral biology of Calliandra tweediei Benth. (Fabaceae)
}

\author{
Fernanda da Silva Cardoso ${ }^{[1]}$, Ernani Augusto Ochekoski Mossanek ${ }^{[2]}$, Luiz Antônio Acra ${ }^{[3]}$ \\ [1] Bióloga bacharel,Herbário da Pontifícia Universidade Católica do Paraná (PUCPR),Curitiba, PR - Brasil, e-mail: dynhah@hotmail.com \\ [2] Graduando do Herbário HUCP, Bacharelado em Biologia pela Pontifícia Universidade Católica do Paraná (PUCPR), \\ Curitiba, PR - Brasil. \\ [3] Biólogo especialista do Herbário HUCP, Pontifícia Universidade Católica do Paraná (PUCPR), Curitiba, PR - Brasil, e-mail: \\ luiz.acra@pucpr.br
}

\section{Resumo}

Foi realizado o estudo da biologia floral e do modo de reprodução de Calliandra tweediei Benth., da família Fabaceae Benth. Compreendeu duas fases: a primeira, em campo, constando a contagem, identificação e observação dos visitantes e seus comportamentos nas flores, além de testes de reprodução com verificação da ocorrência de autogamia, geitonogamia e xenogamia, considerando a reprodução natural (controle); a segunda, em laboratório, constou de testes de presença de osmóforos, guias de néctar, viabilidade polínica e receptividade do estigma. Os estudos demonstraram que Calliandra tweediei Benth. é autocompatível, apresentando baixa produção de frutos. Houve produção apenas nos tratamentos de geitonogamia. Os visitantes encontrados foram: Apis melifera, Augochlora sp., Brachygastra sp., Misumena vatia, Polybia paulista, Polybia sp., Polistes sp., Trigona spinipes, Chrisomellidae não identificado, Lepidoptera não identificado, Diptera não identificado, Formicidae não identificado. Pelo comportamento, somente Apis melifera e Trigona spinipes foram consideradas polinizadoras, e os demais como não polinizadores. Não foi constatada a presença de osmóforos. Os estames desempenham papel de guias de néctar. A viabilidade polínica representa mais de $90 \%$. Os testes de receptividade estigmática não foram conclusivos.

Palavras-chave: Biologia floral; Polinizadores; Apis melifera; Autocompatível; geitonogamia.

\section{Abstract}

The study of floral biology and the way of reproduction was analyzed in Calliandra tweediei Benth., from family Fabaceae Benth. It understood two phases: the first one, in field, consisting the counting, identification and observation from visitors and its behavior in the flowers, beyond 
tests of reproduction with verification of the autogamy occurrence, geitonogamy and xenogamy, considering the natural reproduction (control); the second one, in laboratory, consisted in tests of presence of osmophores, nectar guides, polinic viability and stigma's receptivity. The study had demonstrated that Calliandra tweediei Benth. it's autocompatibility species, and presents low production of fruits. There has been production only on geitonogamy treatments. The frequent visitors were: Apis melifera, Augochlora sp., Brachygastra sp., Misumena vatia, Polybia paulista, Polybia sp., Polistes sp., Trigona spinipes, Chrisomellidae (not identified), Lepidoptera (not identified), Diptera (not identified), Formicidae (not identified). Through the behavior, only Apis melifera and Trigona spinipes had been considered polinizators, and the rest as pillage. There has not been evidenced the presence of osmophores. The stamens play role of nectar guides. The polinic viability represents more than $90 \%$. The tests of receptivity of stigma had not been conclusive.

Keywords: Floral biology; Polinizators; Apis melifera; Autocompatibility; Geitonogamy.

\section{INTRODUÇÃO}

A família Fabaceae Benth. possui cerca de 650 gêneros e 18.000 espécies (1) e é uma das mais numerosas entre as Angiospermas, perdendo em número apenas para as Orchidaceae e Asteraceae. Possuem diversos hábitos, podendo ser anuais ou perenes, subarbustos, arbustos, lianas e árvores, que vivem em vários ambientes, latitudes e altitudes (1).

A taxonomia das Fabaceae possui ainda muitas controvérsias, havendo duas tendências principais: uma que prefere manter uma unidade da família, chamada de Leguminosae ou Fabaceae, com subfamílias - Mimosoideae, Caesalpinioideae e Faboidae (ou Papilionoideae), e a outra interpretação trata essas três subfamílias como famílias, reunindo-as na Ordem Leguminales ou Fabales. A segunda vertente, embora tenha sido predominante entre os taxonomistas, foi abandonada com a utilização de dados moleculares de sistemas filogenéticos como o APG III, porém pode ser utilizada por ter alguns trabalhos que generalizem as Fabaceae e também pela existência de alguns gêneros transicionais entre os três grupos, de cunho anatômico (1).

Têm como distribuição geográfica todos os habitats da Terra, com exceção das regiões geladas (Ártico e Antártida). São relativamente escassas na Nova Zelândia, mas particularmente abundantes em países tropicais como o Brasil, onde se destacam na composição das florestas nativas e fazem parte das centenas de espécies produtoras de madeira valiosa. A origem das fabáceas é um assunto ainda não muito esclarecido, mas sabe-se que durante o Eoceno (65 a 70 milhões de anos) as subfamílias Mimosoideae,
Caesalpinioideaee Faboidae já estavam bem estabelecidas e com ampla dispersão geográfica. Apesar da grande diversidade florística, são poucos os gêneros endêmicos de fabáceas na América do Sul (1).

O gênero Calliandra Benth. possui mais de 150 espécies de arbustos e pequenas árvores que possuem grande valor ornamental por apresentarem um aspecto exótico das suas inflorescências e também por uma rusticidade que permite que se adaptem as diferentes paisagens (2).

Estudos enfocando a biologia e a morfologia floral são características essenciais para o entendimento das relações existentes entre as estruturas das flores e destas com os seus polinizadores, garantindo assim o sucesso reprodutivo da espécie vegetal (3). Atualmente, estão sendo considerados imprescindíveis para o desenvolvimento de programas de melhoramento e de conservação genética (4), colaborando para o sucesso de plantios com espécies nativas.

O presente trabalho tem como objetivo estudar os aspectos da morfologia e a biologia floral e o sistema de reprodução em Calliandra tweediei Benth., além de descrever o comportamento das espécies polinizadoras.

\section{MATERIAL E MÉTODOS}

O estudo foi realizado na Pontifícia Universidade Católica do Paraná, Câmpus Curitiba, nos meses de junho a outubro de 2006. Foram determinadas duas áreas de estudo que apresentavam características físicas diferentes: uma com sombra durante todo o dia e alta umidade, e outra com sol na 
maior parte do dia e baixa umidade. O critério de escolha das plantas foi o número e posição dos botões para facilitar a realização das atividades.

O início dos trabalhos em campo foi marcado pela estiagem prolongada no Estado do Paraná. Sendo assim, a condição meteorológica foi caracterizada por dias quentes, secos e sem nuvens. As observações foram realizadas em horários variados, entre 9 e 18 horas, totalizando 28 horas de esforço. Os dados foram obtidos por observações visuais, em dias não consecutivos, realizando-se contagens a cada 10 minutos (seis contagens por hora). Para determinar a frequência, foi utilizado o maior número de visitantes de cada espécie por hora, obtido com as contagens. Como objetivo, visou identificar as espécies visitantes, seus horários de coleta e descrever o comportamento das espécies polinizadoras. Identificar as espécies de acordo com os horários de visitação mostra-se necessário para determinar a frequência de visita de cada espécie. Através da descrição do comportamento dos insetos foi possível diferenciá-los em polinizadores e não polinizadores. Os insetos foram coletados manualmente, com auxílio de uma câmara mortífera.

Botões florais foram previamente isolados com tule e manteve-se assim após as polinizações. Os estudos do sistema reprodutivo foram realizados por polinizações manuais. As plantas que vivem na área sombreada não recebem visitantes e, por isso, o único teste realizado foi o de autopolinização espontânea para verificar qual a taxa de sucesso naquela área. Neste caso, três inflorescências foram isoladas e três marcadas como controle. Com as plantas que recebem sol na maior parte do dia, além das autopolinizações espontâneas, foram realizados testes de polinizações manuais, sendo considerados os seguintes tratamentos: autopolinização, com o pólen da própria flor; geitonogamia, que consiste em transferir o pólen da antera de uma flor para o estigma de uma outra flor na mesma planta; e polinização cruzada por xenogamia, com troca de pólen de plantas diferentes. As flores foram emasculadas para obtenção de resultados mais precisos. Para estes, foram escolhidas oito inflorescências para cada teste e para o controle.

Em laboratório, quatro experimentos foram realizados com inflorescências já abertas e com produção de pólen, sem nenhum tipo de diferenciação na escolha.

O primeiro foi a verificação da presença ou ausência de osmóforos por meio do teste do vermelho neutro (5). A ocorrência da coloração das partes da flor ou inflorescência indica a presença ou não de osmóforos.

O segundo teste para a ocorrência ou ausência de guias de néctar foi determinada pelo teste com hidróxido de amônio (5). A absorção e reflexão dos raios UV é representada pela alteração da cor das partes florais para o roxo.

Para testar a viabilidade do pólen, lâminas foram preparadas com o pólen coletado e carmim acético e, sobre eles, colocou-se uma lamínula. Ao microscópio, a verificação da alteração de cor do pólen indica que este é viável.

Por último, foi testada a receptividade do estigma com água oxigenada que é indicada pela efervescência da estrutura.

\section{RESULTADOS E DISCUSSÃO}

A espécie Calliandra tweediei Benth. é representada por indivíduos de até três metros de altura. Os ramos, pecíolos e pedúnculos são revestidos por densa pilosidade sedosa. As folhas, alternas e bipinadas, apresentam pecíolo glanduloso, estípulas de aproximadamente $1.5 \mathrm{~cm}$, oval-estriadas e 2 a 6 pares de pinas, com 3 a $7 \mathrm{~cm}$ de comprimento. Os folíolos são lineares ( $7 \mathrm{~mm} \times 1 \mathrm{~mm})$, variáveis de 25 a 35 pares por pina, glabros com exceção do bordo sedoso ciliado e com nervura central. As flores são bissexuadas, actinomorfas, heteroclamídeas, agrupando-se formando vistosas inflorescências em forma de capítulos axilares solitários, tendo estames vermelhos de aproximadamente $4 \mathrm{~cm}$. Cada inflorescência possui, em média, 14 flores. A literatura cita que a floração estende-se de setembro a janeiro, porém ela tem ocorrido durante o ano todo, provavelmente pelos diversos distúrbios ambientais existentes atualmente. Androceu tipicamente com 20-30 estames e gineceu de ovário súpero, unicarpelar, unilocular, às vezes divididos por falsos séptos, em geral multiovulado. $\mathrm{Na}$ base da folha e dos folíolos existem articulações chamadas, respectivamente, de pulvinos e pulvínulos. Os legumes, principal característica das fabáceas, são lenhosos e com 5 a $7 \mathrm{~cm}$ de comprimento por 8 a $9 \mathrm{~mm}$ de largura e apresentam margem engrossada e de cor castanha, sendo revestidos por indumento velutino. É uma espécie heliófila e seletiva higrófila, habita preferencialmente a orla da floresta ciliar e margem de cursos d'água (1). 
A antese das flores de $C$. tweediei Benth., normalmente, é iniciada no período da noite, mas a abertura dos botões da inflorescência é irregular, ocorrendo também durante o dia. Por isso, não foi possível cronometrar nem determinar as fases de abertura. De um modo geral, ao abrirem as sépalas, os pistilos parecem estar preparados antes dos estames, apresentando-se eretos enquanto os estames ainda estão enrolados sobre si mesmos ao redor do gineceu. $\mathrm{O}$ fenecimento começa a partir do quarto dia depois do início do florescimento e pode durar aproximadamente oito dias.

Os resultados dos testes realizados com o sistema reprodutivo indicam que a espécie é autocompatível. Em ambas as áreas, determinadas pelas diferenças das condições físicas, houve a formação de apenas um fruto, com uma semente, decorrente da fecundação por geitonogamia. O número reduzido de frutos tem sido encontrado em leguminosas, e as causas podem variar entre as espécies (6). Em C. tweediei Benth., fatores genéticos e a deficiência na polinização, pela pouca produção ou a liberação de pólen e o fato do estigma ser muito pequeno, podem ser citadas como as principais causas da baixa produção de frutos.

O fruto obtido levou cerca de 40 dias para completar seu desenvolvimento (desde a data da polinização).

Oconceito degeitonogamia ainda é confuso. Literaturas especializadas consideram este processo como fertilização cruzada, por envolver duas flores. Atualmente, porém, parâmetros genéticos têm sido muito utilizados para melhor visualizar, compreender e determinar certas características ou procedimentos. Comisso, torna-se possível considerar a geitonogamia como um caso especial de autofertilização, já que apresentam resultados semelhantes. Apesar de ser usado pólen de outra flor para o experimento, elas pertencem à mesma planta. Isto significa que possuem o mesmo material genético e o sucesso dos seus cruzamentos causa diminuição da variabilidade genética. O desenvolvimento de frutos de autopolinização sugere que a autoesterilidade pode estar associada à depressão endogâmica (6).

Em alguns casos, verificou-se em algumas inflorescências que, enquanto a maior parte das flores murchava, secava e caia, uma delas continuavalevemente fixa na base. A hipótese que surge é a existência de um sistema de autoincompatibilidade tardio, ou seja, condições que impedem o desenvolvimento e a maturação dos frutos formados a partir da autopolinização. Age impedindo a germinação dos grãos de pólen, o crescimento dos tubos polínicos e até mesmo a penetração dos óvulos. Estudos feitos sobre mecanismos de incompatibilidade em plantas tropicais, o número de espécies apresentando o sistema de autoincompatibilidade tardia, ou autoesterilidade, vêm crescendo em relação àquelas com sistemas convencionais de autoincompatibilidade (6).

A não formação de frutos pela autopolinização espontânea, de acordo com Freitas e Oliveira (6), representa que a espécie não pode se reproduzir sem o auxílio dos seus visitantes, afastando também a ideia de apomixia.

Apesar de não terem sido encontrados nectários no interior da flor, a presença de néctar só pode ser verificada com o teste de absorção e reflexão de raios ultravioleta. Constatou-se a presença de guias de néctar, principalmente nos estames. Segundo Vogel (7), moscas e abelhas parecem preferir flores com alta concentração de açúcares no néctar. Considerando que $C$. tweediei Benth. é polinizada principalmente por abelhas, provavelmente a concentração de açúcares no seu néctar seja alta. $\mathrm{O}$ resultado do teste de osmóforos foi negativo, confirmando que estes são ausentes. Portanto, a espécie apresenta como recursos de atração a absorção e reflexão dos raios ultravioleta e o néctar. O pequeno número de grãos pólen e o estigma pequeno também podem ser considerados características atrativas para insetos.

No teste de viabilidade do pólen, cerca de 90\% dos grãos de pólen foram corados, indicando que a viabilidade é alta. Diferente do que é citado pela literatura, a floração de $C$. tweediei $B$ Benth. ocorre durante quase todo o ano e, apesar disso, a produção do pólen parece não perder a qualidade, não havendo diferença na época em que foi realizado o teste. Contudo, poucos grãos de pólen são disponibilizados durante o dia, conforme as observações. Nesse estudo não foi possível definir se isso é uma característica que sempre esteve presente ou tornou-se uma estratégia reprodutiva no decorrer da sua evolução. Como tal, o pólen pode ser liberado aos poucos no decorrer do dia para que sempre haja o contato do polinizador com o pólen, permitindo mais de um visitante por flor. Segundo Thomson e Thomson (8), o padrão de apresentação de pólen pode afetar o sucesso reprodutivo masculino da planta e, consequentemente, o sucesso reprodutivo feminino. Portanto, esse método é eficaz por possibilitar que mais grãos de pólen cheguem a mais flores, por meio de um maior número de animais visitantes.

O teste da receptividade do estigma não foi conclusivo, pois mesmo após algumas tentativas 
há grande dificuldade em visualizar a efervescência no estigma. Porém, observando-se os estigmas das flores in vivo, é possível diferenciar os receptivos: eles apresentam a superfície brilhante e pegajosa e, quando não mais receptivos, tornam-se marrons e murchos. Esta característica também foi observada por Silva et al. (4), em Cnidosculus juercifolius Pax \& K. Hoffm. Descreveram a aparência do estigma no momento da antese como: "[...] apresentavam-se receptivos e a superfície brilhante e pegajosa, e no dia seguinte tornaram-se amarelados e marrons [...]". Aceita-se a confirmação do resultado positivo do teste de receptividade do estigma através da observação do aspecto visual.

Entre os frutos formados, o número de sementes varia, de 1 até 6 ou 7 na mesma vagem. $O$ fato da produção de poucas sementes pode ter relação com o fato das sementes não necessitarem de um ambiente limitado. Apesar de não fazer parte dos objetivos do trabalho, duas sementes foram coletadas e plantadas. Germinaram dentro de 4 a 5 dias, com condições normais - dentro de um recipiente plástico tampado, entre folhas de papel toalha umedecidos, conservado em temperatura ambiente. Um experimento similar foi realizado por Silveira, Fernandes e Fernandes (9), testando se temperatura e luminosidade influenciam na germinação das sementes da espécie Calliandra fasciculata Benth. e concluíram que a temperatura interfere no tempo de desenvolvimento das sementes e que estas são insensíveis à luz.

Calliandra tweediei Benth. é exclusivamente entomófila, ou seja, os insetos são os únicos indivíduos que visitam e polinizam suas flores. A atividade de coleta parece estar relacionada às condições meteorológicas, principalmente com a temperatura. Começa por volta das 9 horas, aumentando em número conforme aumenta a temperatura no dia e diminui ao entardecer. Considerando-se as espécies que foram registradas em pelo menos quatro horários, Apis melifera apresentou maior frequência entre $14 \mathrm{e}$ 15 horas, Trigona spinipes entre 9 e 10 horas, Polybia sp. entre 15 e 16 horas e, por último, Polybia paulista entre 12 e 13 horas. Boiça Júnior, Santos e Passilongo (10) consideraram que fatores meteorológicos podem influenciar uma maior incidência de Trigona spinipes em certas horas do dia. Com Caesaria grandiflora, Machado e Oliveira (7) também consideraram serem relevantes esses fatores.

A identificação dos grupos resultou em: 1 espécie de Coleoptera, 1 de aranha (Misumena vatia), 2 espécies de abelhas (Apis melifera e Trigona spinipes), e 5 vespas (Augochlora sp., Brachygastra sp., Polistes sp.,
Polybia paulista e Polybia sp.). Foram observados, mas não coletados 1 Hymenoptera (formiga), 1 Lepidoptera (borboleta) e2Diptera (moscas). A mosca, a borboleta, a formiga, o "besouro" e 2 das espécies de vespas foram observadas apenas uma vez cada. Da borboleta foi possível fazer um registro fotográfico, mas de má qualidade. Não foi possível visualizar as moscas e a formiga para tentar descrevê-las. De acordo com Kiill e Costa (11), os insetos visitam as flores Annona squamosa L. em busca de alimento, abrigo e local de cópula. Em C. tweediei Benth., as abelhas investiam em busca de alimento. As vespas às vezes procuravam a recompensa floral, mas também foi observado que uma das espécies de vespa pousou sobre o cálice e fazia movimentos esfregando suas patas no aparelho bucal. As sépalas destas flores são bastante pilosas e, aparentemente, as vespas coletam estes pelos, enrolando-os para carregar com mais facilidade. As moscas estavam pousadas sobre as folhas eo coleóptero sobre as inflorescências, provavelmente, apenas procurando abrigo. A presença da formiga entre as sépalas das flores pode indicar que, além do abrigo, ela encontrou uma fonte de açúcares acidentalmente.

Por possuírem maior frequência de visitas e ter contato com as estruturas reprodutivas durante a coleta do néctar, Apis melifera (abelha africanizada) e Trigona spinipes (Irapoá ou abelhas-cachorro) são as espécies consideradas polinizadoras. Com exceção das vespas que, eventualmente, podem encostar-se aos estames levando pólen para o estigma, os demais insetos são considerados pilhadores.

Verificou-se que as espécies polinizadoras não sobrepõem seus horários de visitação. As observações foram feitas em três plantas localizadas nas áreas que recebem sol. Um dado interessante sobre a não sobreposição de horários: duas das plantas utilizadas são separadas por uma rua, mas de um lado registrou-se maior frequência de $A$. melifera $(95,1 \%)$ e, do outro, T. spinipes foi predominante $(92,3 \%)$. Tornando este fato mais interessante ainda, na terceira planta utilizada para observações, T. spinipes inicia suas atividades de coleta antes de $A$. melifera, a partir das 9 horas. Aproximadamente às $11 \mathrm{~h} 30 \mathrm{~min}$, A. melifera começam a aparecer, caracterizando uma fase de transição, na qual o número de irapoás diminui e o de abelhas africanizadas aumenta. Nesta planta, a espécie predominante é a T. spinipes, representando cerca de $78 \%$.

De acordo com Boiça Júnior, Santos e Passilongo (10), as abelhas irapoá podem ser danosas às espécies que visitam. Em um estudo com maracujazeiros, constataram que, além de coletar pólen e néctar, elas recortam partes de folhas 
jovens e das flores, para auxiliar na construção dos seus ninhos, causando a queda destas partes e, assim, torna a planta menos atrativa às mamangavas que são os principais polinizadores do maracujazeiro. Este fato, porém, não foi observado em $C$. tweediei Benth. Suas flores continuavam com a mesma aparência e o fenecimento ocorreu sem influência nenhuma de fatores exógenos.

O comportamento de forrageamento desenvolvido por A. melifera e T. spinipes são, em geral, muito parecidos. Ambas sobrevoam a planta e pousam em uma inflorescência de preferência que não tenha nenhum outro indivíduo. Considerando-se uma inflorescência totalmente aberta, o pouso pode ocorrer de três maneiras: indo diretamente à base da flor pela parte superior ou basal, e uma terceira forma em que o indivíduo pousa na lateral de uma flor periférica abraçando os estames e o estilete. Antes de entrar na inflorescência, ele sobe até a superfície dos estames e do estigma. Quando chega à base da flor, afasta as peças reprodutivas, inserindo a probóscide no interior do cálice. Pode caminhar de uma flor para outra fazendo o mesmo procedimento. A saída tem duas opções: caminham pelas flores, até chegar à periferia ou escalam a flor, enrolando seu corpo nos estames e, ao chegar à superfície, param e, sem encostar-se nas anteras, batem as asas e voam. Permanece na flor, em média, 20 segundos. Foram observados alguns indivíduos de $A$. melifera pousando em botões florais. Neste caso, procuravam a fissura central das sépalas e inseriam seu aparelho bucal, e quando necessário, forçavam um pouco a abertura com os tarsos. Diferenciando, T. spinipes é mais seletiva quanto às flores escolhidas para coletar, sobrevoando a planta em busca das inflorescências mais vistosas e permanecendo por um tempo maior no interior delas, aproveitando todo o néctar fornecido.

\section{CONSIDERAÇÕES FINAIS}

A antese de C. tweediei Benth. é irregular, normalmente ocorrendo no período da noite. A partir do quarto dia de abertura, o fenecimento das inflorescências éiniciado durando aproximadamente oito dias. Houve formação de um fruto, por geitonogamia. $\mathrm{O}$ fruto demora cerca de 40 dias para se desenvolver completamente. A espécie foi considerada autocompatível. Constatou-se a presença de guias de néctar, principalmente nos estames, mas sem estruturas nectaríferas. Os osmóforos são ausentes. Os testes de receptividade do estigma não foram conclusivos. O número de sementes pode variar de 1 até 6 ou 7 na mesma vagem. Sendo uma espécie exclusivamente entomófila, somente Apis melifera e Trigona spinipes foram consideradas espécies polinizadoras, as demais foram denominadas pilhadoras. Os grupos encontrados foram: 1 Coleoptera, 1 aranha (Misumena vatia), 2 espécies de abelhas (Apis melifera e Trigona spinipes) e 5 vespas (Polybiapaulista, Polybia sp., Polistes sp., Brachygastra sp. e Augochlora sp.). Foram observados, mas não coletados, 1 Hymenoptera (formiga), 1 Lepidoptera (borboleta) e 2 Diptera (moscas). A atividade de coleta começa às 9 horas, aumentando em número conforme aumenta a temperatura no dia e diminui ao entardecer. Apis melifera apresentou maior frequência entre 14 e 15 horas, Trigona spinipes entre 9 e 10 horas, Polybia sp. entre 15 e 16 horas e, por último, Polybia paulista entre 12 e 13 horas. O comportamento de forrageamento desenvolvido por A. melifera e T. spinipes são semelhantes. Esta difere por ser mais seletiva quanto às flores que visita e pelo tempo que permanece coletando.

\section{AGRADECIMENTOS}

Ao HUCP pelo material fornecido e espaço físico para a realização dos experimentos laboratoriais. Ao Professor Gabriel Augusto Rodrigues Melo, especialista em Hymenoptera, do Departamento de Zoologia da Universidade Federal do Paraná, pela identificação taxonômica dos insetos coletados.

\section{REFERÊNCIAS}

1. Marchiori JNC. Dendrologia das angiospermas: leguminosas. Santa Maria: UFSM; 1997.

2. Risch Neto O. Equipe caliandra. [citado 13 set 2006]. Disponível em: www.aracmidia.art.br/ caliandra/flor_caliandra.pdf

3. Lenzi M, Orth AI. Fenologia reprodutiva, morfologia e biologia floral de Schinus terebinthifolius Raddi (Anacardiaceae), em restinga da Ilha de Santa Catarina, Brasil. Biotemas. 2004;17(2):67-89.

4. Silva LMM, Aguiar IB, Viégas RA, Mendonça IFC. Biologia reprodutiva de Cnidosculus juercifolius Pax \& K. Hoffm (Euphorbiaceae). Revista de Biologia e Ciências da Terra. 2006;6(2):25-34. 
5. Bezerra ELS, Machado IC. Biologia floral e sistema de polinização de Solanum stramonifolium Jacq. (Solanaceae) em remanescente de Mata Atlântica, Pernambuco. Acta Botânica Brasílica. 2003;17(2):247-57.

6. Freitas CV, Oliveira PE. Biologia reprodutiva de Copaifera langsdorffii Desf. (Leguminosae, Caesalpinioideae). Rev Bras Bot. 2002;25 (3):311-21.

7. Machado AO, Oliveira PEAM. Biologia floral e reprodutiva de Casearia grandiflora Camb. (Flacourtiaceae). Rev Bras Bot. 2000;23 (3):283-90.

8. Carmo RM, Franceschinelli EV. Polinização e biologia floral de Clusia arrudae Planchon \& Triana (Clusiaceae) na Serra da Calçada, município de Brumadinho, MG. Rev Bras Bot. 2002;25(3):351-60.

9. Silveira FAO, Fernandes F, Fernandes GW. Light and temperature influence on seed germination of Calliandra fasciculata Benth. (Leguminosae). Lundiana. 2005;6(2):95-7.

10. Boiça Jr. AL, Santos TM, Passilongo J. Trigona spinipes (Fabr.) (Hymenoptera: Apidae) em espécies de maracujazeiro: flutuação populacional, horário de visitação e danos às flores. Neotropl Entomol. 2004;33(2)135-9.

11. Kiill LHP, Costa JG. Biologia floral de Annona squamosa L. (Annonaceae) na região de Petrolina, PE. Ciência Rural. 2003:33(5):851-6.

Recebido: 12/05/2007

Received: 05/12/2007

Aprovado: 21/07/2007

Approved: 07/21/2007 